\title{
The Concept of Applying the Polyjet Matrix Incremental Technology to the Manufacture of Innovative Orthopaedic Corsets - Research and Analysis
}

\author{
Zuzanna ŁĄPIEŚ $^{\mathrm{a}, 1}$, Przemysław SIEMIŃSKI ${ }^{\mathrm{b}, 1}$, Jarosław MAŃKOWSKI $^{\mathrm{b}, 1}$, \\ Jakub LIPNICKI ${ }^{\mathrm{c}}$, Łukasz ŻRODOWSKI ${ }^{\mathrm{d}}$, Piotr ŻACH ${ }^{\mathrm{b}}$, Michał FOTEK ${ }^{\mathrm{b}}$ and \\ Łukasz GOŁĘBIEWSKI ${ }^{\mathrm{b}}$ \\ ${ }^{a}$ Akademia Sztuk Pięknych $w$ Warszawie, Wydziat Wzornictwa \\ ${ }^{b}$ Politechnika Warszawska, Wydzial Samochodów i Maszyn Roboczych, Instytut \\ Podstaw Budowy Maszyn \\ ${ }^{c}$ EUROMILK \\ ${ }^{d}$ Amazemet sp. z o.o.
}

\begin{abstract}
Paper presents the concept of using digital materials to produce, by 3D printing, personalized orthopaedic corsets. Project assumes that corset created on the basis of a 3D scan and patient's $\mathrm{x}$-ray, after posture correction in a dedicated program, will guarantee anatomical fit. Using additive manufacturing will allow to print shell and padding in one piece, without perceptible boundaries. Smooth combination of variable stiffness materials will allow precise positioning of the pressure surface with optimal shape. Soft padding protects against abrasions and microholes allow body to breathe. Using transparent and multicolour materials will allow creating an individual style corset. To implement the work, research was performed on materials used in PolyJet technology (new material is created in manufacturing process and has properties depending on proportion of base materials). Nonlinear tensile characteristics were obtained. Various models of hyperelastic materials were tested, parameters were identified and Drucker's stability criteria were examined. Using FEM, stiffness and strength of structure was tested. Values of stresses in structure and surface forces in body contact areas were determined. Corset closing pressure and corset opening were simulated.
\end{abstract}

Keywords. Orthopedic corset, posture defects, juvenile scoliosis, spine, 3D printing, PolyJet Matrix, digital materials, hyperelastic materials, model identification, FEM analysis

\section{Introduction}

Scoliosis is a lateral curvature of the spine - instead of a straight line, the spine is S or C-shaped. It can cause asymmetry of the waist and shoulder blades, rib hump, shoulder and hip irregularities. It is the lateral curvature of the spine, measuring at least $10^{\circ}$ on the X-ray determined by the Cobb method [1]. Untreated cases of idiopathic scoliosis

1 Corresponding Author, Mail: zuzanna.lapies@asp.waw.pl, przemyslaw.sieminski@pw.edu.pl, jaroslaw.mankowski@pw.edu.pl 
in adolescents (AIS) may progress and severe cases are at increased risk of various disease problems and mortality [2]. Particularly problematic are juvenile scoliosis, which start at the age of 4-10 years and deepen rapidly at puberty [3]. Scoliosis is the most common spinal deformity in school age children. Approximately 3 million new cases of this condition are diagnosed in the United States every year, the majority of which are idiopathic scoliosis in adolescents [4, 5]. Around 29,000 adolescent scoliosis surgeries are performed in the United States every year [5]. In many non-surgical AIS treatments, corset therapy (brace) is the only potentially effective method of preventing curve progression and the resulting need for surgery [6].

The consultation with Dr Waldemar Szymanik, Head of the Department of Children's Scoliosis in Mazovian Rehabilitation Centre "Stocer" in KonstancinJeziorna shows that in Poland annually about 3000 children require conservative scoliosis treatment and about 1000 surgical ones. Girls aged 10-15 years have scoliosis on average 7 times more often than boys.

The main element used in juvenile scoliosis treatment is an orthopedic corset. The corset is worn 22-23 hours a day and taken off only for exercise and bathing. After 3 months, pellets that increase the correction are glued inside. After 6 months the corset is replaced with a tighter one. The correction lasts from 6 months to several years, depending on the reason and degree of curvature.

The corset works by applying pressure on the arch of spine curvature and supporting it in two places on the opposite side, providing space for tissue outlet. This stops the progression of the curvature. Then, by introducing gradual pushing of the tissues surrounding the spine, the correct posture is forced (Figure 1).

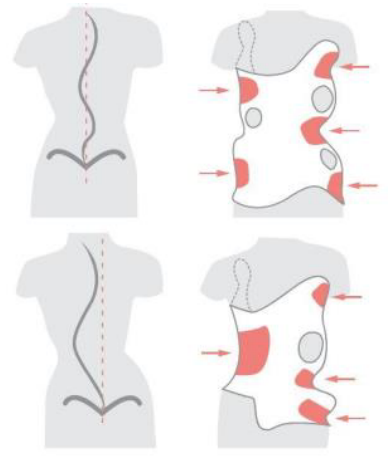

Figure 1. Corset operation - three-point pressure principle.

Making a corset requires a lot of knowledge and skills. It is necessary to create a model on the basis of which the corset will be made. The model is made using two methods: gypsum casting or milled model based on a 3D scan. The most popular and currently the cheapest method is the use of gypsum casting. However, this method requires exceptional qualifications, as it is performed manually (Figure 2). The method using 3D scanning technology is more expensive but less burdensome for the patient (Figure 3). The next step is thermoforming and - again - manual treatment (Figure 4).

The product obtained in this way is very frequently uncomfortable and not very aesthetic (Figure 5-a). Its aesthetics can be improved (Figure 5-b), but there is still the problem of fitting, fasteners and hygiene, corsets are non-breathable products.

Cooperation of many people with an orthopaedic doctor is required for proper making of a corset. Any corrections and a new corset making are done by a technician on behalf of the doctor. Both the execution, as well as corrections and modifications 
require a high-class specialist in this field and a very large experience gained while working with many patients.

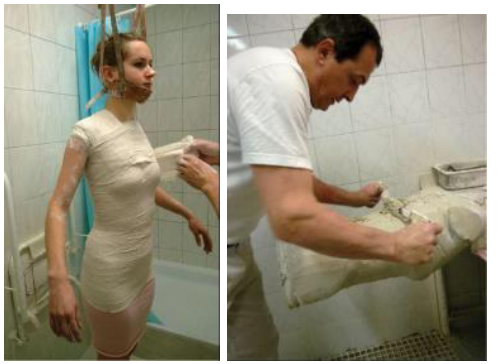

Figure 2. Making a corset model by gypsum casting.
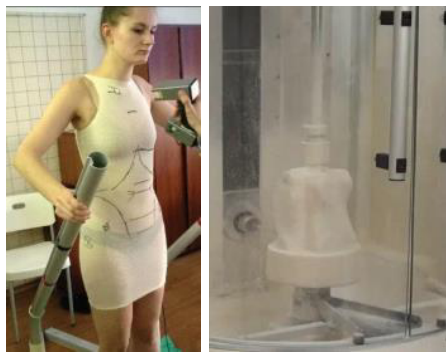

Figure 3. Making a corset model by scanning and milling.
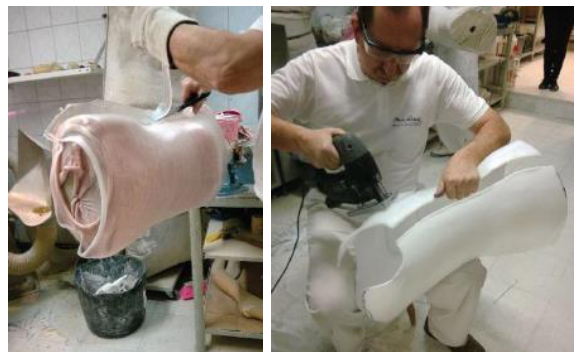

Figure 4. Thermoforming of a corset.

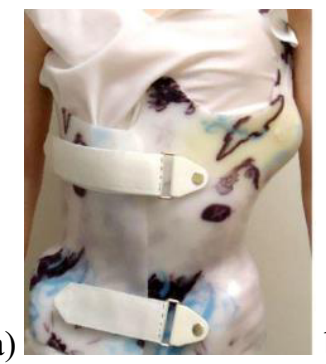

b)

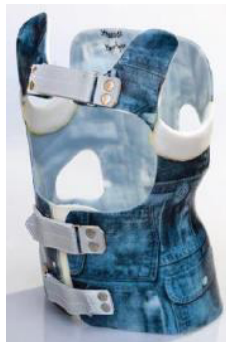

Figure 5. Examples of corsets.

Use of $3 D$ printing in orthopedics

3D printing technology in combination with new imaging methods (3D scanning, CT) allows for effective elimination of many of the identified problems in the field of orthopaedic braces. Examples include innovative wrist orthoses [7]. It uses a hybrid 
production methodology that applies three-dimensional printing and injection moulding technology to create an orthosis, and the problem of gypsum casting is solved by a three-dimensional scanning method. Therefore, the proposed hybrid model significantly reduces production time and costs [8]. Similar solutions are successfully used in foot braces [9-11].

Currently, the listed methods of making orthopaedic orthoses are not cheap. However, taking into account the dynamic development of these technologies, printed orthoses will become cheaper. The Andiamo company estimates that in the nearest future their prices will be lower by $80 \%$ in comparison to traditional ones, and the time of production of the final product will be shortened to 2 days [12].

\section{$3 D$ printing in the production of orthopaedic corsets}

There are many examples of the use of 3D printing in, widely understood, orthopedics in literature. 3D printing is used both pre-operatively for surgical planning [13] and in the education of resident doctors and patients. It also found its place in the operating room, where it is used to produce customized surgical instruments or patient-specific implants. A number of authors highlight the significant benefits of using 3D printing for specific indications in spinal surgery. Although the use of this technology is often still in its infancy, it is stressed that it is a technology of the future. This is evidenced by many articles summarizing the use of this technology in medicine [14-17].

Most of the articles considering 3D printing in orthopedics focus on implants. The usage of $3 \mathrm{D}$ printing in orthosis production is a relatively new idea. This applies especially to orthopedic corsets e.g, „Lelio Leoncini, an Italian doctor specializing in Physical Medicine and Physical Therapy, began 3D-printing experimental "orthopedic corsets" in 2014." [18]

It can be stated that there are many companies that offer corsets prepared with the use of $3 \mathrm{D}$ printing technology $[12,14,18,19]$, but there is no corset mentioned in the literature that would implement all functions described in this project. Regardless of the method of manufacturing, there are usually two drawbacks: an additional inner layer is needed; when the curvature declines, another corset must be manufactured, due to the need to change the shape of corrective elements.

\section{Aim and basic assumptions}

The aim of this work is to propose a solution to eliminate most of the problems discussed. Generally, it has been assumed that using modern technologies and materials, it will be possible to develop a methodology for manufacturing corsets which becomes widely available for those in need, makes it easier to conduct treatment, increase accessibility and speed up the process of treatment, be relatively cheap to perform, easy to use, improve comfort and hygienic conditions, and look so that young people will not be ashamed to use them.

It was also assumed that the orthopaedic corset will be made on the basis of doctor's recommendations and a 3D scan of the patient's figure. Based on the results of the scan a 3D CAD model of the patient's torso is developed. Then a corset model is created. Based on the doctor's instructions, the position and shape of the correction elements are determined and then added to the model. The corset is made of various materials: external coatings are to provide adequate stiffness and strength, internal 
coatings - correction and comfort. In addition, the corset should enable making adjustments at every visit to the doctor and be unique in visual terms.

\section{Methods and materials}

\subsection{Consultation with the medical community and patients}

The work began with consultations with the environment of doctors, technicians and patients of the Mazovian Rehabilitation Centre "Stocer". Many opinions of the environment related to the use of orthopaedic corsets have been collected.

\subsection{Design, CAD and FEM model}

Using a system CAD/CAM implemented in Vigo Ortho-Poland, which is working basing on different data (anthropological measurement, x-ray picture, photographic documentation, measurements made during the Patient's visit), a 3D model were created. Next, using Rhinoceros 3D CAD system ver. Rhino 6.6 the design were created. Basing on the model from Rhino, using the Solid Works system the CAD model for the FEM were made. The FEM models were created using Abaqus CAE.

\subsection{Technology}

Taking into account the dynamic development of incremental methods and their increasing capabilities [20-22], it was assumed that the product would be made using $3 \mathrm{D}$ printing. This is closely linked to the choice of material, as the ideal should be characterised by a number of often conflicting features. The ideal material should: be biocompatible (allowed for prolonged contact with the body and not causing any allergies); waterproof (it cannot absorb sweat and dirt and has to allow the corset to be washed); provide adequate strength (it is supposed to carry loads ensuring stability, forces acting on the corset's fastenings, be characterized by resistance to cracking); provide a porous structure; enable a smooth, imperceptible and controlled transition from hard to soft surfaces; be UV resistant; allow the surface to be personalised with colour and relief; allow the effect of lightness to be achieved using transparent materials; the price of materials and production should allow the purchase of a new corset every 6-12 months.

Based on the authors' experience [23-26] detailed market research was carried out in the field of technology and material selection. It was not possible to find material meeting all of the above mentioned criteria. However, at this stage, due to the possibilities that allow for the realization of the basic assumptions of the project, digital materials $^{2}$ from the groups were used: Tango and Vero and PolyJet Matrix technology from Stratasys. In the chosen method, the product is created by mixing two materials with different characteristics (stiffness and strength), and the final properties are

\footnotetext{
2 Digital materials - The term digital materials, according to the definition proposed in 2007 by George A. Popescu MIT [27], refers to materials made of different components that meet the following criteria: ,The set of all the components used in a digital material is finite (i.e. discrete parts). The set of the all joints the components of a digital material can form is finite (i.e. discrete joints). The assembly process has complete control over the placement of each component (i.e. explicit placement).”.
} 
obtained during the production of the finished element [28]. It allows to create structures that have changing properties in the cross-section of the structure. It is therefore perfectly suited for a project where relatively high stiffness and strength of the outer coatings and soft and susceptible inner coatings are required.

\subsection{Materials}

As mentioned, the project required a selection from a wide range of material properties [29] that would provide the right strength-stiffness parameters. Tango group materials are characterized by non-linear elasticity and the ability to achieve large elastic deformations (hyper-elastic materials), while Vero group materials have characteristics more similar to linear materials and achieve significantly lower elastic deformations. In order to verify the characteristics tensile tests were conducted [30].

\subsection{Analyses}

Finite Element Method (FEM) was used - implemented in Abaqus CAE 2019 system. The coefficients of constitutive models were identified on the basis of the obtained characteristics [30]. The next stage was the analysis of stability of the identified models using Drucker criteria [31, 32]. Based on the results obtained and using the Finite Element Method, numerical models were built, in which the rigid parts of the corset were defined as made of Vero25 material; while Tango85 and TangoBlack were chosen for the flexible parts.

A number of FEM analyses were carried out (including a set of utility loads, e.g.: corset opening, pumping correction elements, checking clamps and latches), which allowed to verify design assumptions, choose materials and introduce necessary modifications. [33]

\section{Results}

\subsection{Problem map}

On the basis of consultations with doctors, technicians and patients, a map of problems was defined, which is shown in Figure 6.

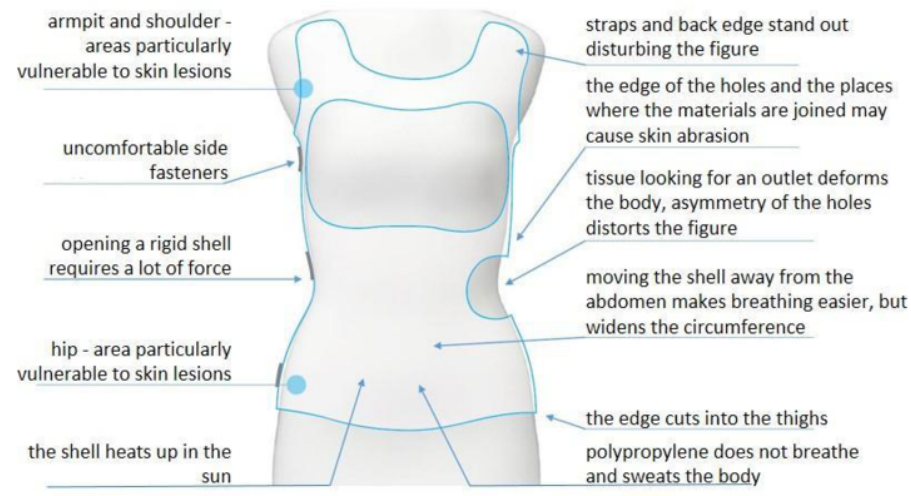

Figure 6. Orthopaedic corset - problem map. 


\subsection{Identification of material models and numerical analyses}

The obtained results of numerical research are presented [34] and widely described in [33] and [35].

\subsection{Corset design}

These works led to the design of the corset (Figure 7), which is characterized by stiff outer shell and soft, fitted to the patient's silhouette, inner layer; adjustment of the shoulder straps pressure by pumping; possibilities to influence the stiffness of the structure by means of embossing and reliefs; soft profiling in the armpit area; soft hip protection; soft abdomen protection; buckles acting on the kandahar principle; adjustable by changing the pressure of the peloton - correction elements; two-stage, spring-loaded back and shoulder straps finish, preventing the edges of the corset from sticking out; perforations enabling the removal of heat and moisture from the body; soft spaces in any place and shape; elastic elements along the spine making it easier to put on and take off and improving comfort of use.

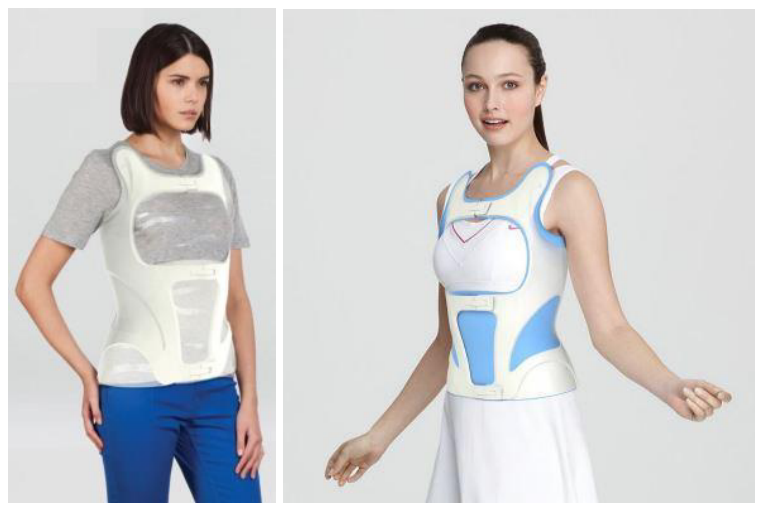

Figure 7. Designed corset.

\section{Conclusions - Corset design for the 21 st century}

The market for medical products is quite hermetic. The main emphasis focuses on effectiveness. Therefore, products such as orthopaedic corsets are very often made as strictly medical products - without the involvement of specialists from various fields such as: industrial design, material engineering, modern methods: manufacturing, research and analysis. In this project, in order to obtain a design for the 21 st century, it was decided to combine the forces of the above mentioned industries with the experience of orthopaedic doctors and technicians with many years of experience in making corsets. This was complemented by a series of consultations with the patient community, which is to be the main beneficiary of the achievements of this work. Using modern design methods, 3D scanning, incremental technologies, digital material capabilities and numerical computational methods, lead to creating a design that meets most of the postulates, which have been recorded in the work.

The design is a base with very high development potential. Apart from the aforementioned advantages, it has one of a vast importance: the possibility of more 
frequent and much faster corrections, performed directly by an orthopaedic surgeon namely: a change in the strength of the corrective elements by changing the pressure in the "pellets" - which will translate into better results of the treatment.

On the downside, the material still has to be worked on. The material used in the project among others: can be allergenic, has a sharp smell, swells under the influence of moisture, is not biostable, and is relatively expensive. However, the test elements made allow for an optimistic perception of the project.

Especially if its developmental capabilities are taken into account, such as the ability to monitor wearing time (extremely important in the case of young people) - the possibility of installing sensors to record the history of use, especially the pressure in the cushions of correction elements, strains, forces in closures, etc. Or, the comfort of use test - assessment of the pressure on the patient's body - will allow for the optimization of the structure at the design stage.

The design was developed in cooperation:

- Doctors from the Mazovian Rehabilitation Centre STOCER, e.g. Dr Waldemar Szymanik, orthopaedic surgeon traumatologist, Head of the Scoliosis Unit

- Orthotics specialists from: Orthopaedic Laboratory Mark Protetik Non-public Health Care Facility

- $\quad$ VIGO Ortho-Poland

- $\quad$ BIBUS MENOS Sp. z o.o.

- Academy of Fine Arts, Faculty of Industrial Design

- Warsaw University of Technology, SiMR Faculty, IPBM, Manufacturing Technology Faculty

- Warsaw University of Technology, SiMR Faculty, IPBM, Material Strength Laboratory

- Warsaw University of Technology, Faculty of Materials Science

\section{References}

[1] W. P. Bunnell, Selective screening for scoliosis, Clinical orthopaedics and related research, 2005, No. 434, pp. 40-45, doi:

10.1097/01.blo.0000163242.92733.66.

[2] D. Y. T. Fong et al., A meta-analysis of the clinical effectiveness of school scoliosis screening, Spine, 2010, Vol. 35, No. 10, pp. 1061-1071, doi: 10.1097/BRS.0b013e3181bcc835.

[3] M. Tyrakowski, T. Kotwicki, and J. Czubak, Adolescent idiopathic scoliosis with rapid progression - a case report, Scoliosis, 2012, Vol. 7, S1, doi: 10.1186/17487161-7-S1-P17.

[4] T. A. Mirtz, M. A. Thompson, L. Greene, L. A. Wyatt, and C. G. Akagi, Adolescent idiopathic scoliosis screening for school, community, and clinical health promotion practice utilizing the PRECEDE-PROCEED model, Chiropractic \& Osteopathy, 2005, Vol. 13, No. 1, p. 25, doi: 10.1186/1746-134013-25.

[5] CLEAR Scoliosis Institute, Scoliosis Statistics. [Online]. Available: https://clearinstitute.org/learning-about-scoliosis/scoliosis-statistics/ 
[6] S. L. Weinstein, L. A. Dolan, J. G. Wright, and M. B. Dobbs, Effects of bracing in adolescents with idiopathic scoliosis, The New England journal of medicine, 2013, Vol. 369, No. 16, pp. 1512-1521, doi: 10.1056/NEJMoa1307337.

[7] Y.-J. Chen, H. Lin, X. Zhang, W. Huang, L. Shi, and D. Wang, Application of 3D-printed and patient-specific cast for the treatment of distal radius fractures: initial experience, $3 D$ printing in medicine, 2017, Vol. 3, No. 1, p. 11, doi: 10.1186/s41205-017-0019-y.

[8] H. Kim and S. Jeong, Case study: Hybrid model for the customized wrist orthosis using 3D printing, J Mech Sci Technol, 2015, Vol. 29, No. 12, pp. 5151-5156, doi: 10.1007/s12206-015-1115-9.

[9] Y. H. Cha et al., Ankle-Foot Orthosis Made by 3D Printing Technique and Automated Design Software, Applied bionics and biomechanics, 2017,Vol. 2017, p. 9610468 , doi: 10.1155/2017/9610468.

[10] K. S. Gibson, J. Woodburn, D. Porter, and S. Telfer, Functionally optimized orthoses for early rheumatoid arthritis foot disease: a study of mechanisms and patient experience, Arthritis care \& research, 2014, Vol. 66, No. 10, pp. 14561464, doi: 10.1002/acr.22060.

[11] S. Telfer, J. Pallari, J. Munguia, K. Dalgarno, M. McGeough, and J. Woodburn, Embracing additive manufacture: implications for foot and ankle orthosis design, BMC musculoskeletal disorders, 2012, Vol. 13, p. 84, doi: 10.1186/1471-247413-84.

[12] Naveed Parvez CEO, Rethinking orthotics. [Online]. Available: https:// www.healtheuropa.eu/andiamo-rethinking-orthotics-2/84936/ (accessed: May 15 2020).

[13] M. Galvez et al., Use of Three-dimensional Printing in Orthopaedic Surgical Planning, Journal of the American Academy of Orthopaedic Surgeons. Global research \& reviews, 2018, Vol. 2, No. 5, e071, doi: 10.5435/JAAOSGlobal-D17-00071.

[14] Q. Yan et al., A Review of 3D Printing Technology for Medical Applications, Engineering, 2018, Vol. 4, No. 5, pp. 729-742, doi: 10.1016/j.eng.2018.07.021.

[15] M. Javaid and A. Haleem, Additive manufacturing applications in orthopaedics: A review, Journal of clinical orthopaedics and trauma, 2018, Vol. 9, No. 3, pp. 202-206, doi: 10.1016/j.jcot.2018.04.008.

[16] M. A. Golovin, N. V. Marusin, and Y. B. Golubeva, Use of 3D Printing in the Orthopedic Prosthetics Industry, Biomed Eng, 2018, Vol. 52, No. 2, pp. 100-105, doi: 10.1007/s10527-018-9792-1.

[17] B. Garg and N. Mehta, Current status of 3D printing in spine surgery, Journal of clinical orthopaedics and trauma, 2018, Vol. 9, No. 3, pp. 218-225, doi: 10.1016/j.jcot.2018.08.006.

[18] B. Coxworth, 3D Printing: Building a better corset - with 3D printing. [Online]. Available: https://newatlas.com/wasp-3d-printed-scoliosis-corset/46403/ (accessed: May 15 2020).

[19] I. Molnár and L. Morovič, Design and manufacture of orthopedic corset using 3D digitization and additive manufacturing, IOP Conference Series: Material Science Eng., 2018, Vol. 448, 12058, doi: 10.1088/1757-899X/448/1/012058.

[20] D. K Mills, Future Medicine: The Impact of 3D Printing, J Nanomater Mol Nanotechnol, 2015, Vol. 04, No. 03, doi: 10.4172/2324-8777.1000163.

[21] A. S. M. Kamran, A Comprehensive Study on 3D Printing Technology, MIT International Journal of Mechanical Engineering, 2016, Vol. 6, No 2, pp. 63-69. 
[22] L. Columbus, The State Of 3D Printing, 2019. [Online]. Available: https:// www.forbes.com/sites/louiscolumbus/2019/05/27/the-state-of-3d-printing-2019/ \#312de1c346c2 (accessed: May 18 2020).

[23] P. Siemiński and G. Budzik, Techniki przyrostowe: Druk drukarki 3D. Warszawa: Oficyna Wydawnicza Politechniki Warszawskiej, 2015.

[24] J. Mańkowski, P. Siemińsk, D. Jurkiewicz, and K. Dominiak, PCL implants 3D printing - the proposal of using beam elements (FEM) in strength analysis, in Proceedings of the Conference Methods \& Tools for CAE - Concepts and Applications, 2015, pp. 267-268.

[25] J. Piękoś, P. Siemiński, and R. Grygoruk, The proposition of the method of increasing dimensional accuracy of additive manufacturing objects, Mechanik, 2016, No. 12, pp. 1910-1911, doi: 10.17814/mechanik.2016.12.548.

[26] Piękoś, J. Grygoruk, R. Siemiński, P., Comparative Analysis of Computed Tomography and 3D Scanning Geometry Acquisition Methods, Machine Dynamics Research, 2017, Vol. 41, No. 3, pp. 13-25.

[27] G. A. Popescu, Digital Materials for Digital Fabrication. [Online]. Available: http://cba.mit.edu/docs/theses/07.08.Popescu.pdf

[28] Stratasys, PolyJet Technology. [Online]. Available: http://www.stratasys.com/3dprinters/technologies/polyjet-technology (accessed: May 18 2020).

[29] FADO, KARTA TECHNICZNA MATERIALÓW POLYJET Q1.2013. [Online]. Available: https://www.fado.info/wp-content/uploads/2014/05/Karta-technicznamateriałów-PolyJet-Q1.2013.pdf

[30] Z. Łąpieś, Ł. Żrodowski i P. Siemiński, Mechanical And Microstructural Analysis of PolyJet Matrix Digital Materials, in Proceedings of the Conference "Methods \& Tools for CAE - Concepts and Applications, 2015.

[31] Dassault Systemes, Abaqus Analysis User's Guide. [Online]. Available: http:// license.mech.northwestern.edu/v6.13/index.html (accessed: Sep. 12 2016).

[32] S. Jemioło, Studium hipersprężystych własności materiałów izotropowych, modelowanie i implementacja numeryczna: Oficyna Wydawnicza Politechniki Warszawskiej, 2002.

[33] J. M. Lipnicki, Badanie numeryczne MES możliwości wykorzystania materiatów stosowanych w technologii PolyJet Matrix do produkcji gorsetów ortopedycznych, Praca magisterska, Samochodów i Maszyn Roboczych, Politechnika Warszawska, Polska, 2016.

[34] J. Mańkowski and J. Lipnicki, Badanie numeryczne możliwości wykorzystania materiałów stosowanych w technologii PolyJet Matrix do produkcji gorsetów ortopedycznych wykonanych z wykorzystaniem druku 3D, in II Krajowa Konferencja Naukowa - Szybkie Prototypowanie, Modelowanie - Wytwarzanie Pomiary, Warszawa-Pruszków, 2016.

[35] J. Mańkowski and J. Lipnicki, Digital Materials - Evaluation of the Possibilities of using Selected Hyperelastic Models to Describe Constitutive Relations, International Journal of Applied Mechanics and Engineering, 2017, Vol. 22, No. 3, pp. 601-612, doi: 10.1515/ijame-2017-0038. 